\title{
Mapping the Intellectual Structure of Communication Trust
}

\author{
Yuan-Duen Lee, Min-Tzu Chen, and Jen-Hwa Kuo
}

\begin{abstract}
The aim of this study is to explore the intellectual structure of communication trust research in the last decade, this study identified the most important publications and the most influential scholars as well as the correlations among these scholar's publications. In this study, bibliometric and tag cloud analysis techniques are used to investigate the intellectual pillars of the communication trust literature. By analyzing 152,181 citations of 3,463 articles published in SSCI journal in commu-nication trust area between 2003 and 2012, this study maps a knowledge network of communication trust studies. The mapping of the intellectual structure of communication trust studies indicates that communication trust has somehow created its own literature and that it has gained the reputation as a legitimate academic field, with communication trust specific journals gaining the status required for an independent research field, such as the Risk Analysis and The Journal of Marketing Information Society. The results of the mapping can help identify the research direction of communication trust research and provide a valuable tool for researchers to access the literature in this area.
\end{abstract}

Index Terms-Communication trust, bibliometric, tag cloud analysis, knowledge network.

\section{INTRODUCTION}

The knowledge system of each discipline is a part of a more general knowledge system as well. It plays a basic role in storage and knowledge spread in various disciplines, journals, articles, books and monographs [1]. In the formal exchange of the three ways (journals, articles, books and monographs), journal articles produce the most useful information because of their timeline as well as the evaluation of the scholars.

This study uses Bibliometrics and Social Network Analysis to understand the evolution to introduced Communication Trust research from 2003 to 2012. This study, in a more objective way, uses Invisible Network of Knowledge (INK) to research the application of the smart structures of Communication Trust field.

This study defines INK as a set of interrelated invisible node. Each node provides a specific purpose for Communication Trust research and any other fields of research. With the quotation and co-citation analysis, this mode can explore the smart structures existing in any field, define its knowledge network, and further depict the process of its knowledge diffusion.

Therefore, referring to a certain discipline in the magazine articles provides an objective measurement to its develop-

Manuscript received January 10, 2013; revised March 12, 2013.

The authors are with the Graduate School of Business and Operations Management, Chang Jung Christian University, Tainan, Taiwan (e-mail: ydlee@mail.cjcu.edu.tw, ava547520@gmail.com, Dynaopto@gmail.com ). ment. It also provides the relative measurement on the special contribution made by the authors, books, journals and the article progress. The past decade has especially seen extensive research on communication trust. Yet even though communication trust has established itself as an academic discipline, its establishment has been a slow process because researchers in this area prefer to publish their best work in more established journals. Another major obstacle to the development of communication trust lies in the subject's unusually high degree of interaction with other disciplines.

This overlapping blurs the boundaries of communication trust and as a result its distinct theoretical model and analytical tools are unjustly attributed to other competing fields. With limited resources contributing to the development of communication trust, the cross-fertilization of ideas between scholars of communication trust will be much more difficult to obtain. Consequently, while there is no doubt that there is an area or field of communication trust, the question remains somehow unclear on what it is, how good its work is, and what are its prospects and needs for future development.

The aim of this study is to provide communication trust researchers with a unique map to better understand communication trust related publications and to provide a systematic and objective mapping of different themes and concepts in the development of communication trust field. This study also attempts to help identify the linkage among different publications and confirm their status and positions in their contribution to the development of communication trust field. The principal methods used are citation and Tag Cloud Analysis.

The purpose of this study is to propose an Invisible Network of Knowledge theory and to explore the evolution development of Communication Trust knowledge structure during the two decades from 1993-2012. This study is to identify the most important publications and researchers, published in SCI and SSCI journals about Communication Trust issues mainly in the years of 1993-2012, as well as to establish the correlation between these publications, and correspond to different research sub-topics in the field, analyze the links between each other, and learn about its developing relationship between the knowledge structure. This study is more trying to help researchers identify the link between the publications of different researchers, as well as to confirm its position and contribution in Communication Trust development.

Therefore, this study is trying to reach the following research purposes by applying Invisible Network of Knowledge (INK):

1) To establish the most important and the most influential scholars, journals, books and articles in Communication Trust study with an objective analysis of the citation. 
2) To provide important insights and impact on current and future research paradigms with the analysis of Invisible network of knowledge in Communication Trust research, as well as the relative research of scholars and practitioners in the management level.

\section{STUdies OF ACADEMIC LitERATURE}

There are a number of techniques that can be used to study a body of literature. Most frequent is the simple literature review where a highly subjective approach is used to structure the earlier work. Objective and quantitative techniques have recently become popular with more databases available online for use. These techniques adopt author citations, co-citations, and systematic review[2] to examine the invisible knowledge network in the communication process by means of written and published works of a given field. These techniques are attractive because they are objective and unobtrusive[3].

Several studies have used the bibliometric techniques to study the literature of management research. For example, Cheng-Hua Wang, Yender McLee, and Jen-Hwa Kuo[4] explored the intellectual structure of digital divide in its early stage of development, using principle component analysis on an author co-citation frequency matrix; Etemad[5] identified the most influential authors and studies in electronic commerce field by using citation analysis; Ponzi[6] explored the intellectual structure and interdisciplinary breadth of digital divide in its early stage of development, using principle component analysis on an author co-citation frequency matrix; Chan, Seow and Tam[7] used citations from accounting dissertations completed during 1999-2003 to provide a ranking of accounting journals; Acedo and Casillas[8] explored the research paradigms of international management research by applying factorial analysis techniques in an author co-citation study; Ramos-Rodriguez and Ruiz-Navarro [9] examined the intellectual structure change of strategic management research by conducting a bibliometric study of the Strategic Management Journal. To the best of our knowledge, no similar study has been conducted on the current research of communication trust. Therefore this study aims to fill a gap in communication trust literature by applying citation and Tag Cloud Analysis to a representative sample of recent research on communication trust collected by the Science Citation Index and Social Sciences Citation Index.

\section{Methodology}

\section{A. Research Method}

In order to understand Communication Trust's in the past, now and the future, this study investigates the relationship of the mutual the wisdom structure during the two decades of 2003-2012. The research methods used in this study covers Bibliometric techniques and Tag Cloud Analysis.

\section{B. Research Process}

First, the selecting from SSCI and SCI database to collect required information about Communication Trust research theme, academics, journals or books, and articles. Second, using Excel analysis technique to reorganize, summarize, classify, rank and filter systematically, and divide the timeline into two periods, 2003-2007 and 2008-2012, to explore the evolution of the intellectual structure in Communication Trust field.

\section{Bibliometric}

Citation analysis method is mainly used to analyze the reference phenomenon or objects of journals, papers, authors, and to explore the relationship between the sources of literature and citation. It can help researchers understand the current state of development of certain disciplines, the literature usage characteristics in the disciplines, correlation within the literatures between disciplines and the future trends of research through citation analysis.

\section{Tag Cloud}

In addition to the advantage of visual creativity and easy-to-use, Tag cloud can be used to assess cluster focus, and is beneficial to the content promotion. It is a good navigation tool to the traditional text based information retrieval system. Tag cloud can also support browsing or unexpected discovery, and can be used as a visual summary of the database content.

In this study, the Science Citation Index (SCI) and Social Sciences Citation Index (SSCI) were used for analysis. The SCI and SSCI are widely used databases, which include citations published in over 3500 world's leading scholarly journals. While there are arguments that other online databases might also be used for such analysis, using SCI and SSCI provided the most comprehensive and the most accepted databases of communication trust publications.

Unlike other prior studies, the data used in this study were not drawn from journals chosen by peer researchers[10]. Instead, the entire databases of SCI and SSCI from 2003 to 2012 served as the universe for analysis. In order to collect the data, we used "key word" method which utilizes the SCI and SSCI databases key word search in article's title and abstract. Using "Communication trust" as key word, this study collected 3,463 journal articles which further cited 152,181 publications as references. The cited references in these papers included both books and journal articles.

\section{RESUlts}

\section{A. Citation Analysis}

To identify the key publications and scholars that have laid down the ground work of communication trust research, citation data were tabulated for each of the 3,463 source documents and 152,181 references using the Excel package. The citation analysis produced interesting background statistics, as shown in the following tables. As shown in Table I, the highly cited communication trust journals between 2003 and 2007 was The Journal of Marketing, Risk Analysis, and The Journal of the American Medical Association (JAMA) are the top three most cited journals.

Table II lists the most cited journals in communication trust area in the decade years, among which Risk Analysis, The Journal of Marketing, and Academy of Management 
Review are the top three most cited journals. The general pattern of the most cited journals shows that communication trust research management, marketing and qualitative specific journals.

Journal articles and books combined, the top five most cited scholar between 2003 and 2007 (the first five years) were Slovic P, Anderson JC, Siegrist M, Frewer LJ and Mayer $R C$ (See Table III). For the second five years, the status of the most important scholars changed. The top five most cited scholars were Slovic P, Siegrist M, Anderson JC, Mayer RC, and Fornell C (See Table IV).

TABLE I: THE MOST FREQUENTLy CiTED JOURNALS: 2003-2007

\begin{tabular}{ll}
\hline \hline & Total \\
Journal & Citation \\
\hline The Journal of Marketing & 810 \\
Risk Analysis & 729 \\
The Journal of the American Medical Association (JAMA) & 509 \\
Academy of Management Review & 474 \\
Journal of Personality and Social Psychology & 404 \\
British Medical Journal & 400 \\
The Journal of Marketing Review & 395 \\
Academy of Management Journal & 385 \\
Organization Science & 362 \\
Social Science \& Medicine & 336 \\
Administrative Science Quarterly & 261 \\
Lecture Notes in Computer Science & 257 \\
Journal of General Internal Medicine & 245 \\
Strategic Management Journal & 239 \\
Journal of Applied Psychology & 229 \\
\hline \hline
\end{tabular}

TABLE II: THE MOST FREQUENTLY CITED JOURNALS: 2008-2012(a)

\begin{tabular}{ll}
\hline \hline Journal & Total Citation \\
\hline Risk Analysis & 1399 \\
The Journal of Marketing & 1306 \\
Academy of Management Review & 881 \\
Journal of Personality and Social Psychology & 784 \\
Social Science \& Medicine & 703 \\
Journal of Marketing Research & 668 \\
\hline \hline
\end{tabular}

TABLE II: THE MOST FREQUENTLY CITED JOURNALS: 2008-2012(b)

\begin{tabular}{ll}
\hline \hline Journal & Total \\
& Citation \\
\hline Organization Science & 654 \\
Academy of Management Journal & 629 \\
Journal of Applied Psychology & 603 \\
The Journal of the American Medical Association (JAMA) & 602 \\
MIS Quarterly & 597 \\
British Medical Journal & 528 \\
Journal of General Internal Medicine & 513 \\
Lecture Notes in Computer Science & 488 \\
Patient Education and Counseling & 444 \\
\hline \hline
\end{tabular}

TABLE III: HighLy CiTED AUTHORS: 2003-2007

\begin{tabular}{llll}
\hline \hline Authors & Frequency & Authors & Frequency \\
\hline Slovic P & 149 & Safran DG & 61 \\
Anderson JC & 115 & Mohr J & 60 \\
Siegrist M & 94 & Walther JB & 59 \\
Frewer LJ & 93 & Sjoberg L & 58 \\
Mayer RC & 77 & Thom DH & 58 \\
Morgan RM & 72 & Mechanic D & 55 \\
Anderson E & 64 & Heide JB & 53 \\
Moorman C & 62 & Rousseau DM & 53 \\
\hline \hline
\end{tabular}

These scholars have the most influence in the development of communication trust area and thus collectively define this field. Their contributions represent the focus of the main research in the field and thus give us an indication of the popularity of certain Communication trust topics as well as their historical values.

TABLE IV: HighLy CiTED AUTHORS: 2008-2012

\begin{tabular}{llll}
\hline \hline Authors & Frequency & Authors & Frequency \\
\hline Slovic P & 348 & Morgan RM & 119 \\
Siegrist M & 237 & Walther JB & 119 \\
Anderson JC & 159 & Sjoberg L & 118 \\
Mayer RC & 143 & Mcknight DH & 104 \\
Fornell C & 132 & Renn O & 99 \\
Frewer LJ & 129 & Poortinga W & 98 \\
Jarvenpaa SL & 129 & Ajzen I & 97 \\
Gefen D & 125 & Fischhoff B & 97 \\
\hline \hline
\end{tabular}

Table III and IV represent the key research themes in a field and give us an indication of the popularity of certain Communication trust topics. The readers can find high citations are associated to what can be termed field-defining titles and they lay down the ground work for the understanding of communication trust as a distinct phenomenon. A comparison between Table III and IV reveals some interesting patterns from the first five years (2003-2007) to the second five years (2008-2012). First, the top four most influential authors in the last five remain the same, indicating their dominant status for the past decade in communication trust studies. This is also true for the top five most influential scholars in the last five years. Second, on the one hand, the most cited publications in the first five years have relatively smaller number of citations, comparing with the publications in the second five years.

The gradual increase in the total citations supports the evolving process of communication trust research as an academic field and the process of gaining more and more recognition in the literature. On the other hand, the most influential papers in the first five years and the second five years do not change much. This indicates the development in communication trust is slow and a few classical works and influential authors still dominate the communication trust research. More efforts and theoretical breakthrough are thus needed in order to further advance the development of communication trust research.

\section{B. Tag Cloud Analysis}

In addition to the advantage of visual creativity and easy-to-use, Tag cloud can be used to assess cluster focus, and is beneficial to the content promotion. It is a good navigation tool to the traditional text based information retrieval system. Tag cloud can also support browsing or unexpected discovery, and can be used as a visual summary of the database content. They provide a visualization of a collection of simple texts by visually depicting the tag frequency by font size. In use, tag clouds can evolve into the associated data source over time. Tag clouds are not only used to display tag sets but are also increasingly applied in other contexts and for various data sets, for instance, in the areas of information visualization or text summarization. As in fig. 1 and fig. 2, they show the core research themes communication trust 
studies, based on sampled article with links of key word than show in the tag clouds.

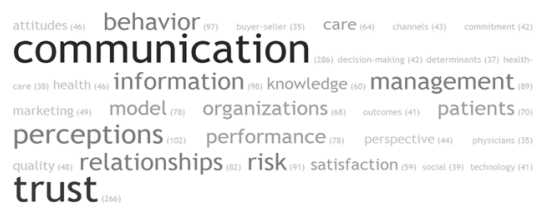

Fig. 1. Tag clouds as key word of web services (2003-2007)

This is produced using software of Tag Crowd web and shows graphically the core areas of interest. The diagrams show that current research in web service area is concentrating on the keyword of essential of communication, trust, perceptions, information, behavior, risk, management, model and performance.

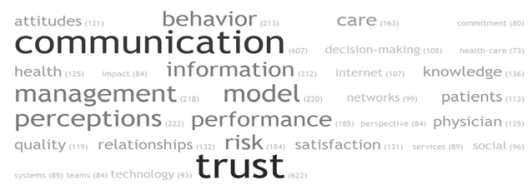

Fig. 2. Tag clouds as key word of web services (2008-2012)

\section{CONCLUSION}

The past decade years have seen extensive research on communication trust. This study investigates communication trust research using citation and Tag Cloud Analysis data published in SCI and SSCI between 2003 and 2012.

The mapping of the intellectual structure of communication trust studies indicates that communication trust has somehow created its own literature and that it has gained the reputation as a legitimate academic field, with communication trust specific journals gaining the status required for an independent research field, such as the Risk Analysis and The Journal of Marketing Information Society. Given that the communication trust is still young and our analysis has shown that it has an evolving structure, it is believed that communication trust publication outlets will gain more popularity and prestige that is required to become a more prominent academic field when we learn more about current paradigms and the key research themes in communication trust studies, how they relate, and what they stand for. With more scholars and more resources contributing to the communication trust area, a better academic environment conducive for research ideas' cross-fertilizing will be formed and communication trust, as a field, will gain more momentum for further development.

\section{REFERENCES}

[1] P. R. Chandy and T. G. F. Williams, "The impact of journal and authors on international business research: A citation analysis of JIBS articles," Journal of International Business Studies, vol. 25, no. 4, pp. 715-728, Oct. 1994.

[2] B. M. Compaine, The Digital Divide: Facing a Crisis or Creating a Myth? Cambridge, Massachusetts: The MIT Press, 2001.

[3] E. Garfield, Citation Indexing: Its Theory and Application in Science, Technology, and Humanities. New York: Wiley, 1979.

[4] C. H. Wang, Y. McLee, and J. H. Kuo, "Mapping the Intellectual Structure of Digital Divide," International Journal of Social Science and Humanity, vol. 1, no. 1, pp. 49-54, May. 2011.

[5] H. Etemad, "E-commerce: The emergence of a field and its knowledge network," International Journal of Technology Management, vol. 28, pp. 776-800, Dec. 2004.

[6] L. J. Ponzi, "The intellectual structure and interdisciplinary breadth of communication trust: A bibliometric study of its early stage of development," Scientometrics, vol. 55, pp. 259-272, Aug. 2002.

[7] K. C. Chan, G. S. Seow, and K. Tam K., "Ranking accounting journals using dissertation citation analysis: A research note," Accounting organizations and Society, vol. 34, pp. 875-885, Aug. 2009.

[8] F. J. Acedo and J. C. Casillas, "Current paradigms in the international management field: An author co-citation analysis," International Business Review, vol. 14, pp. 619-639, Oct. 2005.

[9] A. R. R. Rodriguez and J. R. Navarro, "Changes in the intellectual structure of strategic management research: A bibliometric study of the strategic management journal, 1980-2000," Strategic Management Journal, vol. 25, pp. 981-1004, Oct. 2004.

[10] K. A. Walstrom and L. Leonard, "Citation classics from the information systems literature," Information and Management, vol. 38, pp. 59-72, Dec. 2000.

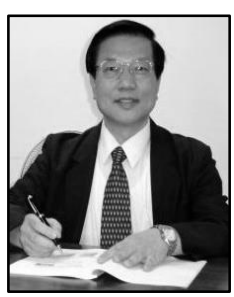

Yuen-Duan Lee is a professor at the Graduate School of Business and Operations Management of the Chang Jung Christian University in Taiwan. He received $\mathrm{PhD}$ degrees from the Education Management and Human Resources in Drake University, U.S.A. His research interests include international business topics, strategic human resource management, organizational behavior and lea dership.

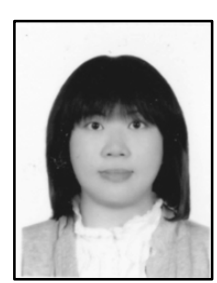

Min-Tzu Chen is a doctoral student at the Graduate School of Business and Operations Management, Chang Jung Christian University in Taiwan. She received MS degree from the Department of Information and Communication in Southern Taiwan University of Science and Technology, Taiwan. Her research interests include consumer culture and behavior, organiza tional behavior and human resource management.

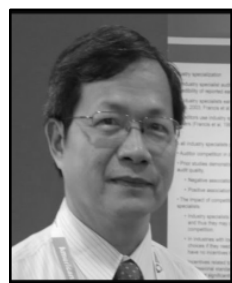

Jen-Hwa Kuo is a doctoral student at the Graduate School of Business and Operations Management, Chang Jung Christian University in Taiwan. He received MS degree from the Graduate Institute of Industrial Economics in National Central University, Taiwan. His research interests include enterprise resource planning, management information system and Accounting. 